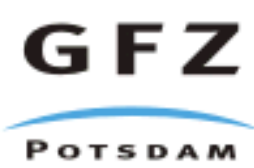

Originally published as:

Ruch, J., Anderssohn, J., Walter, T. R., Motagh, M. (2008): Caldera-scale inflation of the Lazufre volcanic area, South America: Evidence from InSAR. - Journal of Volcanology and Geothermal Research, 174, 4, 337-344

DOI: 10.1016/j.jvolgeores.2008.03.009 


\title{
Caldera-scale inflation of the Lazufre volcanic area, South America: Evidence from InSAR
}

\author{
J. Ruch *, J. Anderssohn, T.R. Walter, M. Motagh \\ GeoForschungsZentrum Potsdam, Telegrafenberg, D-14473, Potsdam, Germany
}

\section{A R T I C L E I N F O}

\section{Article history:}

Received 30 August 2007

Accepted 6 March 2008

Available online 26 March 2008

\section{Keywords:}

volcano deformation

InSAR

caldera

magma chamber

Andes

\begin{abstract}
A B S T R A C T
Collapsed calderas are the structural surface expression of the largest volcanic eruptions on Earth and may reach diameters of tens of kilometres while erupting volumes larger than $1000 \mathrm{~km}^{3}$. Remnants of collapse calderas can be found along the South American volcanic arc and are thought to be inactive. However, this study shows that systems of such dimension may become active in a relatively short period of time without attracting much attention. Using satellite-based InSAR data, a $45 \mathrm{~km}$ wide elongated area of ground deformation was observed in the Lazufre volcanic region (Chile), where no deformation was detected 10 years ago. The deformation signal shows an uplift of up to $\sim 3 \mathrm{~cm} \mathrm{yr}^{-1}$ during 2003-2006, affecting an area of about $1100 \mathrm{~km}^{2}$, comparable in size to super-volcanoes such as Yellowstone or Long Valley. This deformation signal can be explained by an inflating magma body at about $10 \mathrm{~km}$ depth, expanding and propagating laterally at a velocity of up to $4 \mathrm{~km}$ per year. Although it is not clear whether this intrusion will lead to an eruption, its dimensions and the rapid deformation rate insinuate that a potentially large volcanic system is forming.
\end{abstract}

(c) 2008 Elsevier B.V. All rights reserved.

\section{Contents}

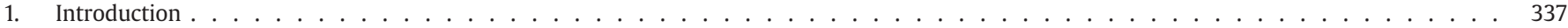

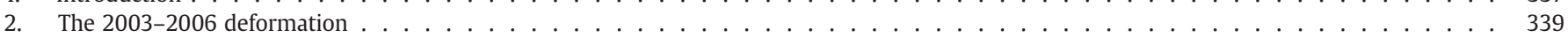

2.1. InSAR data . . . . . . . . . . . . . . . . . . . . . . . . . . . . . . . . . . . . . 339

2.2. Volume and area increase . . . . . . . . . . . . . . . . . . . . . . . . . . . . . . 339

2.3. Source modelling . . . . . . . . . . . . . . . . . . . . . . . . . . . . . . . . . . . . 340

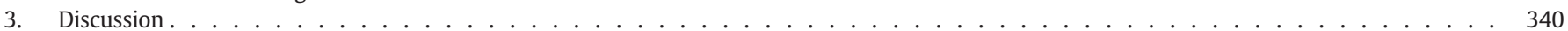

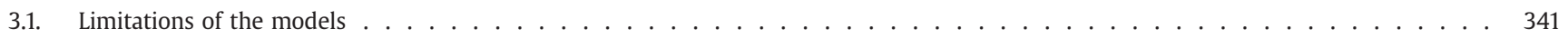

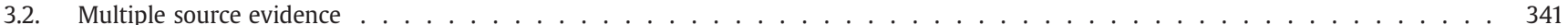

3.3. The comparison to other inflation caldera systems . . . . . . . . . . . . . . . . . . . . . . . . . . 341

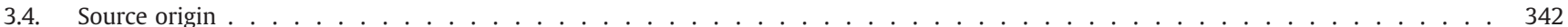

3.5. Earthquake triggering of magma intrusion . . . . . . . . . . . . . . . . . . . . . . . . 343

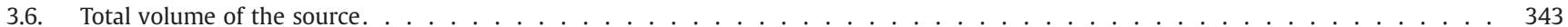

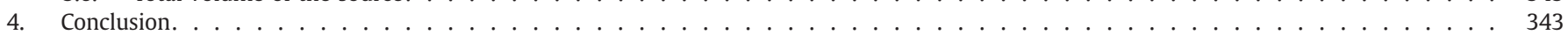

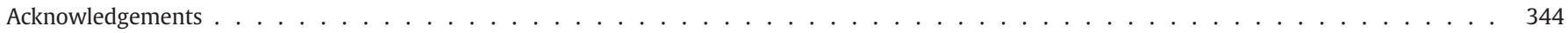

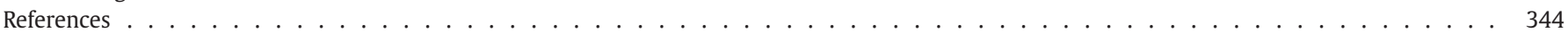

\section{Introduction}

Collapse calderas are subcircular depressions in volcanic areas that are thought to form during rapid evacuation of a shallow crustal magma chamber and are associated with the most devastating type of volcanic eruptions (Williams, 1941; Lipman, 1997). No major caldera-

\footnotetext{
* Corresponding author. Tel.: +49 3312881202; fax: +49 3312881204. E-mail address: jruch@gfz-potsdam.de (J. Ruch).
}

forming eruptions have been witnessed by mankind, except for the Minoan eruption on the Santorini Island ( $3600 \mathrm{BP})$ and the Great Toba caldera eruption (Indonesia) at $71,000 \mathrm{BP}$ that is thought to have drastically reduced the genetic diversity of the human population (Ambrose, 1998). Although the processes acting during caldera eruptions have been extensively studied in the field and laboratory (Cole et al., 2005), the early development of magmatic systems responsible for such eruptions remain poorly understood and controversial. It is well accepted in the literature that large calderas are associated with large crustal magma chambers (de Silva, 1989; Francis et al., 1989; 


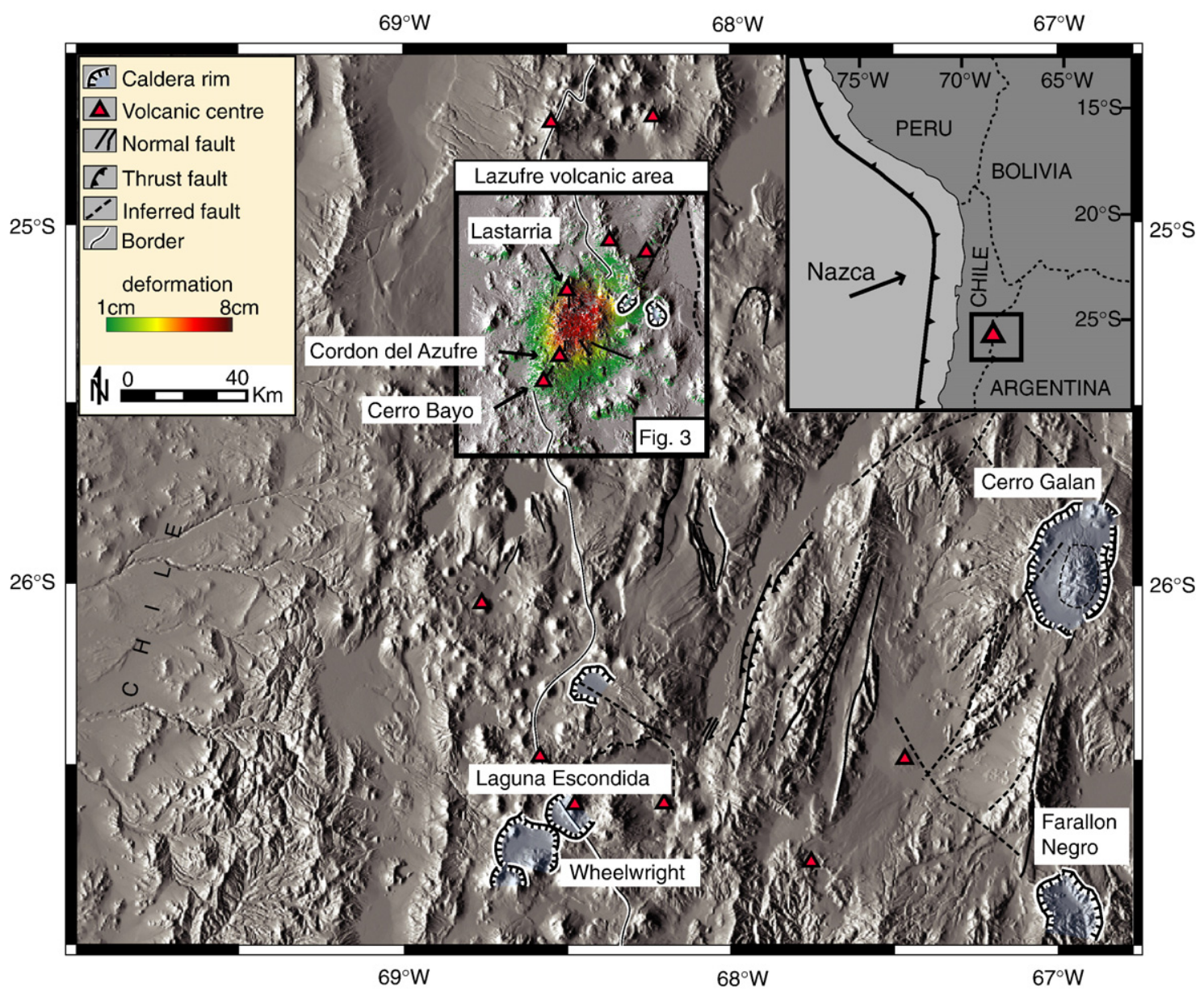

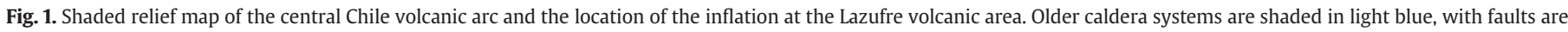
marked by black lines.

Ort et al., 1996; Lipman, 1997; Cole et al., 2005). However, such magma bodies at depth are seldom geophysically constrained and clear evidence of in situ magma reservoirs beneath volcanoes is rare (Marsh, 2000).

The subduction of the Nazca plate beneath South America is responsible for the uplift of the Altiplano-Puna plateau $\left(16^{\circ} \mathrm{S}-26^{\circ} \mathrm{S}\right)$, part of the Central Volcanic Zone $\left(\mathrm{CVZ}, 14^{\circ} \mathrm{S}-28^{\circ} \mathrm{S}\right)$. The thickening of this high-elevated zone leads to extensive crustal melting (de Silva, 1989) that has resulted, during the last 20 million years, in one of the most voluminous explosive volcanic provinces in the world. Caldera collapses and associated ignimbrite deposits represent the dominant type of volcanism in this area, partially superimposed by younger stratovolcano edifices. Chile hosts 36 historically active volcanoes and 16 major calderas, with diameters of up to $50 \mathrm{~km}$ (Lipman, 2000). The Altiplano-Puna plateau is known for its abundance of ancient large caldera collapses that occurred in geologic times, examples being La Pacana $(60 \times 30 \mathrm{~km}$, long and short axis diameters, respectively), and Cerro Galán $(35 \times 20 \mathrm{~km})$.

In this work we focus on the Lastarria-Cordon del Azufre volcanic area ("Lazufre" after Pritchard and Simons, 2002), a region composed of about 40 Quaternary volcanic centres surrounded by older caldera systems (Fig. 1). Inflation of up to $\sim 1 \mathrm{~cm} \mathrm{yr}^{-1}$ during the period 1996-2000 was first observed using satellite SAR interferometry measurements by Pritchard and Simons (2002, 2004). A more recent study showed that the rate of inflation had increased, such that at around 2005 it was $2.5 \mathrm{~cm} \mathrm{yr}^{-1}$ (Froger et al., 2007). Here we analyse newly acquired SAR data from the Envisat satellite for the period 2003 to 2006 to better assess the temporal and spatial evolution of surface deformation at Lazufre, and to determine its source parameters. Analysis of the data suggests that the extent and rate of inflation is further increasing. Using a time series analysis, we are able to constrain the volume

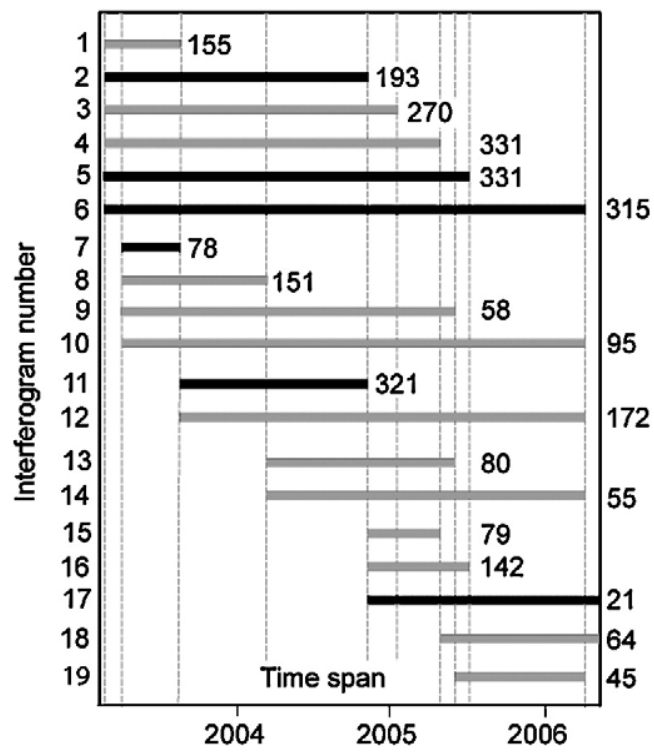

Fig. 2. Time series of the 19 radar interferograms showing deformation at Lazufre from March 2003 to June 2006. The interferograms used for the deformation rate calculations are shown by bold black lines. The numbers on the left are the interferogram's numbers used in the text. The numbers on the right denote the perpendicular baseline in metres. 
change and discuss the dimension of a proposed magma reservoir underlying this area.

\section{The 2003-2006 deformation}

\subsection{InSAR data}

In order to study land-surface deformation in the Lazufre area, we selected 11 Envisat SAR images acquired in descending orbit covering the period between March 2003 and June 2006. We processed the data using the software package SARscape (www. sarmap.ch) and generated 19 interferograms with perpendicular baselines ranging between 20 and $330 \mathrm{~m}$ (Fig. 2). A 3 arc-second SRTM digital elevation model was used to correct for topographic effects and to geocode the interferograms. The differential interferograms were unwrapped using a growing region algorithm (Reigber and Moreira, 1997) to determine the absolute value of the range change. To reduce the InSAR typical noise we applied a low-pass Kernel filter on the geocoded unwrapped results and applied pairwise logic to discriminate between the displacement signal and atmospheric artefacts (Massonnet and Feigl, 1998). Interferograms that show significant artefacts due to topographic, atmospheric or orbital errors were not considered in this study. However, the accuracy of InSAR measurements is still difficult to quantify due to the complexity of the cumulative error estimations (Massonnet and Feigl, 1998; Bürgmann et al., 2000). The coherence of the InSAR pairs in the region is generally high for the observation time period of interest that is between 2003 and 2006. Fig. 3 shows four examples of the interferograms covering time intervals of 0.5 to $3.2 \mathrm{yr}$. The interferograms show the LOS (line-of-sight) displacement, where both the amount and spatial extent of the signal appear to increase with time. The maximum displacement rate is hence $2.8-3 \mathrm{~cm} \mathrm{yr}^{-1}$ for the observation period 2003-2006, which is $\sim 3$ times more than that deduced from earlier InSAR observations for the period 1998-2000 (Pritchard and Simons, 2002) and slightly more than that estimated for the period 2003-2005 (Froger et al., 2007).

\subsection{Volume and area increase}

We now investigate the increasing rate of surface deformation by analysing the volume evolution of the uplifted area. We use interferograms with time spans from 140 up to 1155 days to compute incremental volume changes with time. We mask out the dataset below $1 \mathrm{~cm}$ to avoid the integration of sparse signals present below

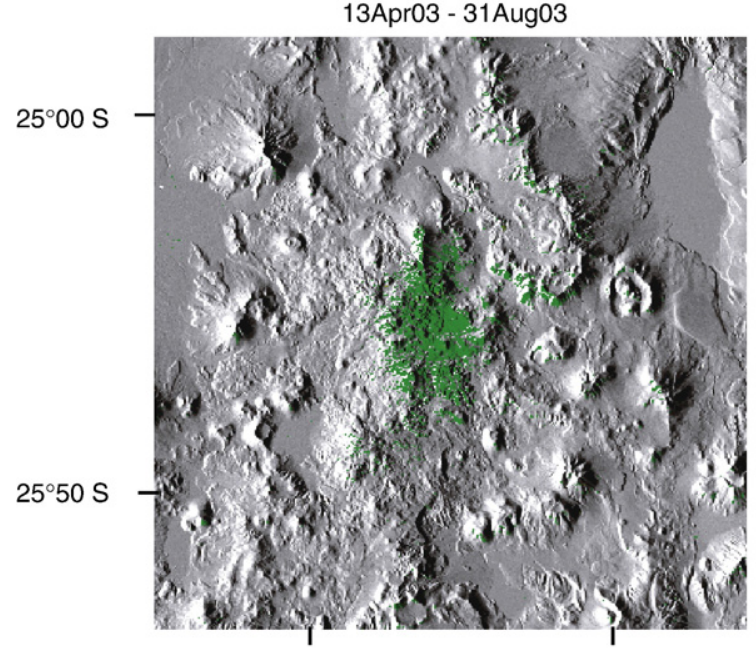

$68^{\circ} 65 \mathrm{~W}$

$68^{\circ} 25 \mathrm{~W}$

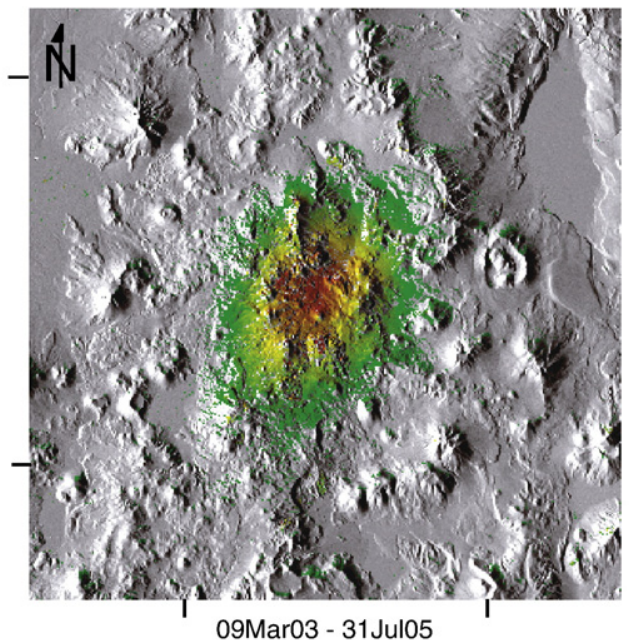

09Mar03 - 31Jul05

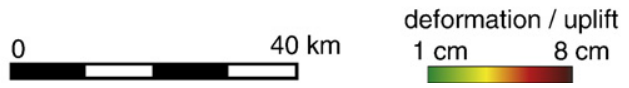

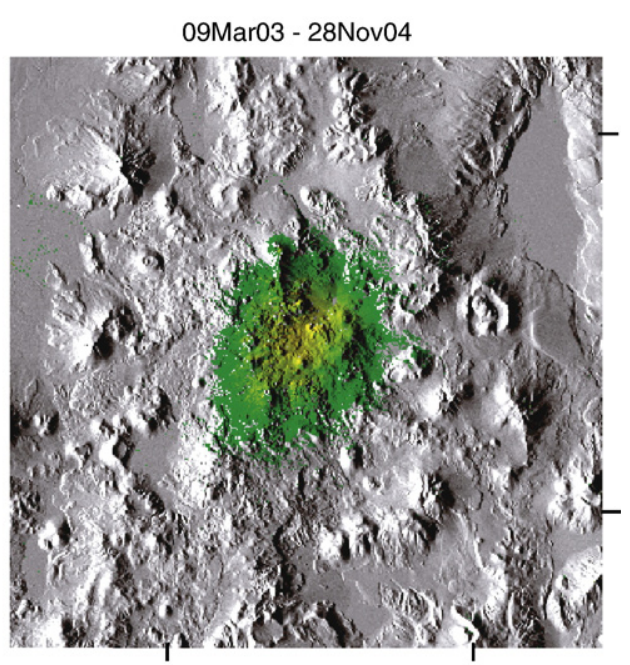

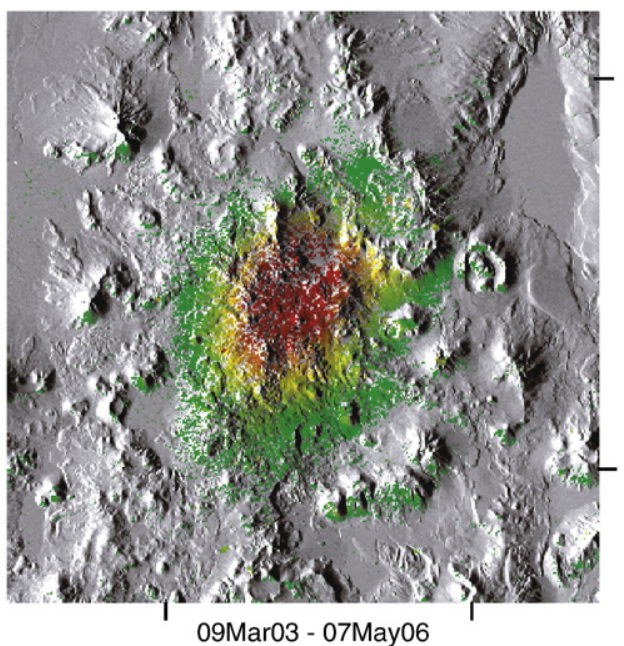

Fig. 3. Unwrapped InSAR data for different temporal baselines. Note that the area and amount of uplift increases with time and that the area of the deformation contains several volcanic centres. 

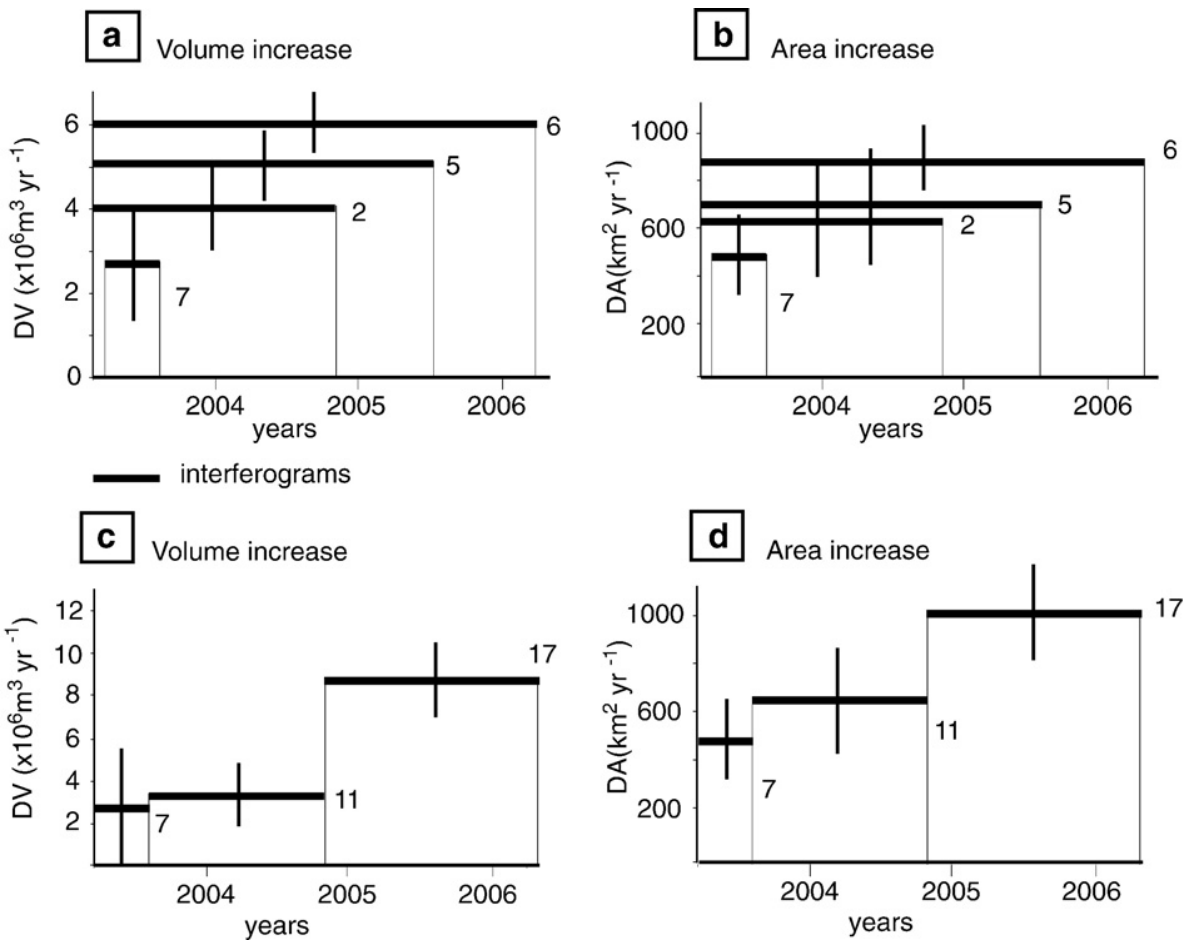

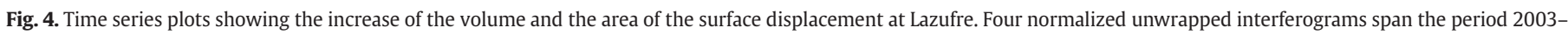

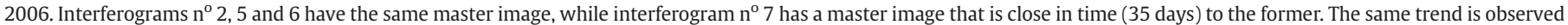
using three other normalized independent interferograms (c, d). Vertical bars indicate the standard deviation assuming $1 \mathrm{~cm}$ deviation in the InSAR measurements.

this threshold. For comparison we select four interferograms that start in 2003 (similar master image) with different time intervals (dissimilar slave images). These volumes are normalized with respect to the time interval they span to obtain the mean annual uplift rate. The results are shown in Fig. 4a. Over the considered time interval, the mean rate of inflation increased from about $3 \pm 1.5$ to $6 \pm 0.74 \times 10^{6} \mathrm{~m}^{3}$ $\mathrm{yr}^{-1}$. The area affected by the deformation enlarged from about $300 \pm$ $158 \mathrm{~km}^{2} \mathrm{yr}^{-1}$ to $900 \pm 124 \mathrm{~km}^{2} \mathrm{yr}^{-1}$ (Fig. 4b). We tested this rate by selecting another set of InSAR data, where the slave image of the first is the master image of the second interferogram, and so on. These yielded volume increases from $3 \pm 1.5$ to $9 \pm 1.9 \times 10^{6} \mathrm{~m}^{3} \mathrm{yr}^{-1}$, and area increases from $300 \pm 158 \mathrm{~km}^{2} \mathrm{yr}^{-1}$ to $1000 \pm 320 \mathrm{~km}^{2} \mathrm{yr}^{-1}$ (Fig. 4c, d). The rates of increase are thus very similar in both cases. As we will show in the next section, the deformation source underlying the Lazufre area is therefore increasing in its dimensions.

\subsection{Source modelling}

In order to characterise the source of the inflation, we performed an inversion in a two-step process. First, we constrain the depth of the source by applying a homogeneous dislocation source, and second, we discretize this source into smaller elements and calculate the distribution of opening.

The InSAR data are fitted using Okada's formulation (1985) to estimate the length, width, depth and uniform opening of a dislocation plane. Regarding the shape of the surface displacement, we constrained the strike (direction of deformation), the ratio between the length and the width, and define the source as horizontal. The inversion is done using a non-linear Levenberg-Marquardt algorithm via the minimization of the mean square misfit (Tarantola, 1987). We find that, for the interferograms inverted, sources with depth from 8.5 to $13 \mathrm{~km}$ provide reasonable fit to the data. Fig. 5 shows the normalized InSAR data, together with the best fitting models derived from the inversion.

In the second working step, we constrain the optimal depth to be at $10 \mathrm{~km}$, enlarge the horizontal plane at lateral edges and discretize it into smaller triangular elements (see also Lundgren and Lu, 2006). We solve for opening on each of the elements using a linear inversion implemented by a boundary element approach (Maerten et al., 2005; Thomas, 1993). Compared to the homogeneous slip models, the distributed slip models show better fits to the InSAR data due to the geometry of the source (Fig. 6). The slip distribution suggests a maximum opening of 5 to $6 \mathrm{~cm} \mathrm{yr}^{-1}$ (Fig. 7), equivalent to a fluid overpressure of about $20 \mathrm{MPa}$, assuming a mean value of $75 \mathrm{GPa}$ for the crust rigidity. Moreover, by comparing the opening distributions for the various interferograms, we obtain information about the lateral expansion of the source. As shown in Fig. 7, the source laterally expands with time, while the rate of volume change doubles over the 3-year time-period, from $6 \times 10^{6} \mathrm{~m}^{3} \mathrm{yr}^{-1}$ to $12 \times 10^{6} \mathrm{~m}^{3} \mathrm{yr}^{-1}$. This is several orders larger than common rates in arc volcanoes (Ingebritsen et al., 1989). Our models suggest that the source expands from about 300 to $650 \mathrm{~km}^{2}$ and is elongated in a NNE-SSW direction. An important implication is that the axes of the source propagate horizontally at a rate of up to about $4 \mathrm{~km} \mathrm{yr}^{-1}$, respectively. Although the total difference of volume $(\Delta V)$ of this assumed magma body is not yet comparable to that of ashflow systems, the spatial dimension of the source and the surface doming is already comparable to that of the largest known calderas. As discussed below, however, the total volume of the source may be much larger than its currently observed volume changes.

\section{Discussion}

During the Quaternary period, about 130 large calderas erupted worldwide (Newhall and Dzurisin, 1988). Of these, about 10 caldera volcanoes are currently in a state of unrest (Siebert and Simkin, 2002) and only a few are closely monitored. One main difficulty is to detect and characterise the magma storage system, an important variable for volcano hazard assessment. As caldera formation requires a shallow crustal magma chamber, the latter could be detected prior to caldera evolution. In this study, we use InSAR data to obtain insights into the evolution of a volcanic area subject to inflation that may be linked to a $>30 \mathrm{~km}$ diameter magma chamber. Our InSAR data suggest that the extent of uplift $>1 \mathrm{~cm}$ is about $1100 \mathrm{~km}^{2}$, centred at $25.25^{\circ} \mathrm{S}$ and 


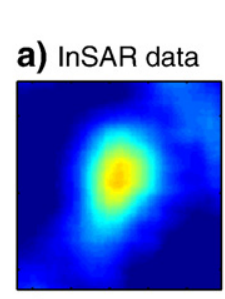

b) Model

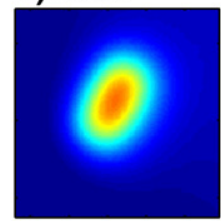

c) Residual

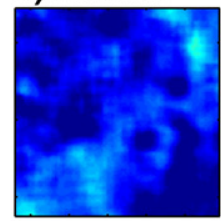

d) Profile

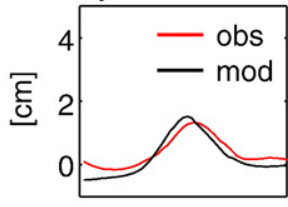

A

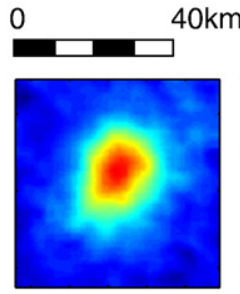

A

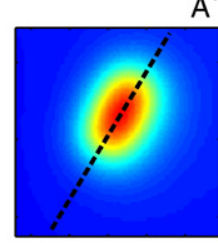

A
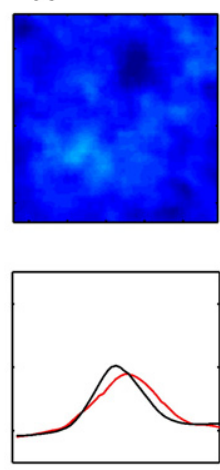
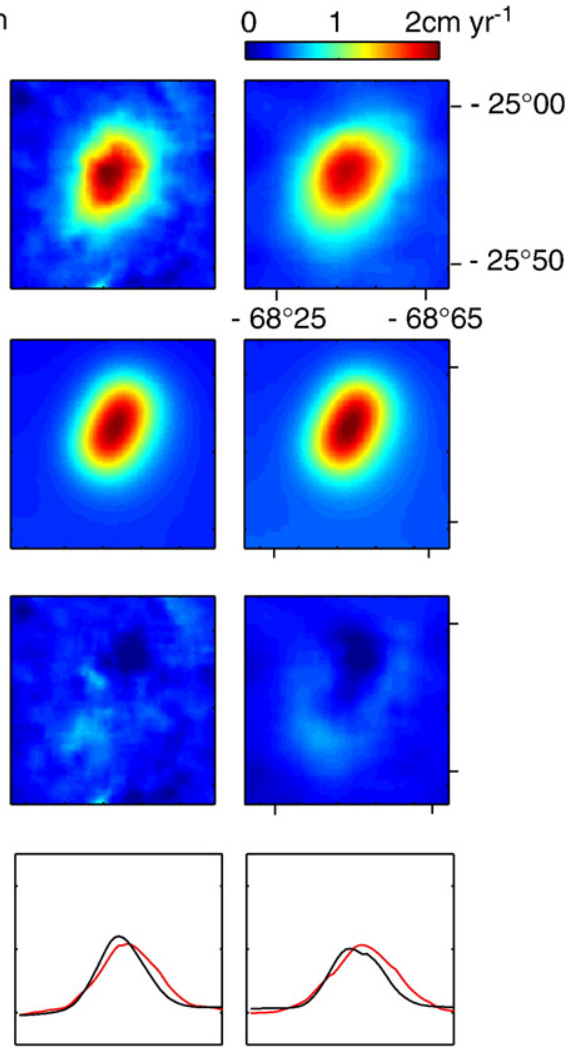

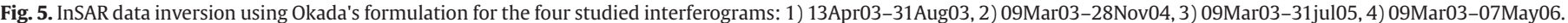

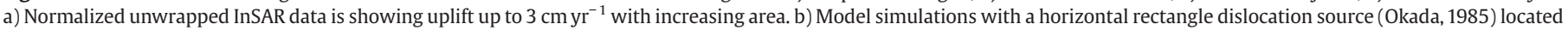
at $10 \mathrm{~km}$ depth. c) Residual test between the InSAR data and the models show a good fit.

$68.49^{\circ} \mathrm{W}$. As proposed by Pritchard and Simons (2004), deformation in this region most probably started in early 1998 and may be related to magma intrusion. Our study reveals that this process continues and has even increased its rate of volume accumulation. We find that the detected normalized displacement rate tripled from 2003 to 2006, and the rate of volume increase has doubled over the same period.

\subsection{Limitations of the models}

Important information for Lazufre volcano complex were retrieved from InSAR data, however, we note that data handling and model building may depend upon the a-priori information available for the study object and the methods applied. Implementations with additional geophysical and petrological data can reduce a part of the actual limitations. The lack of such information does not support more complex model simulations including, for example, crustal heterogeneities that are known to have important effect on the source parameters (Manconi et al., 2007). Uncertainty exists in the source location, strength and finite geometry. For instance, subvertical displacement data alone, without additional horizontal displacement measurements, is limited to constrain unambiguously the geometry of the deformation and subsequently the source parameters (Dieterich and Decker, 1975). Besides modelling limitations, errors in geodetic data may also significantly effect the interpretation. The accuracy of InSAR measurements is still difficult to quantify due to the complexity of the cumulative error estimations (Massonnet and Feigl, 1998; Bürgmann et al., 2000; Hanssen, 2001), and even under ideal conditions, only centimetre accuracy can be estimated in many cases. Therefore, our hypothesis and data interpretation may be influenced by the data quality, atmospheric and topographic artefacts, and filtering techniques applied, as well as simplifications that were necessary for the model calculations.

\subsection{Multiple source evidence}

Froger et al., 2007 proposed a second, smaller source of deformation in the northern part of the anomaly of Lazufre. This smaller source, located $1 \mathrm{~km}$ beneath the Lastarria volcano, is interpreted to represent shallow hydrothermal activity. In this study, we performed a different modeling strategy and therefore obtain slightly different results. While Froger et al. (2007) used uniform source model geometries constrained by InSAR observations to fit the surface deformation pattern, we use distributed slip models. Both are valid methods and complementary approaches and both well reproduce the InSAR signal. Our approach does not resolve the second shallow source, however, it brings new insights into the evolution of the source at depth and allows the estimation of the spatio-temporal evolution and propagation of the intrusion.

\subsection{The comparison to other inflation caldera systems}

The InSAR data presented herein shows that the diameter of the surface inflation is $45 \times 30 \mathrm{~km}$ wide. This dimension implies the presence of an extended magma body, which is also supported by geomorphology: The area displays a regional topographic dome of about $500 \mathrm{~m}$ height which has a central depression crowned by a ring of Quaternary volcanoes (Froger et al., 2007; Pritchard and Simons, 2002). In addition, three major volcano lineaments represented by the Lastarria, two unnamed important volcanic fissures, Cordon del Azufre and Cerro Bayo converge radially to the central depression (see Fig. 1). A dome and an apical depression crowned by a ring of volcanic centres are typical features for regions of inflation and of pre-caldera collapse stages (see also Lipman, 2000).

In order to better place these dimensions in a global context, we compare different inflation regions detected by InSAR. Fig. 8 is a 


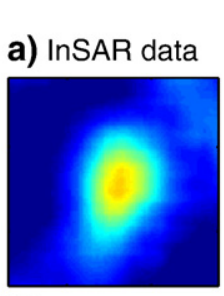

b) Model

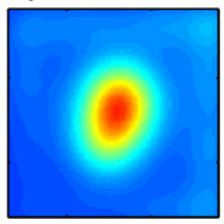

c) Residual

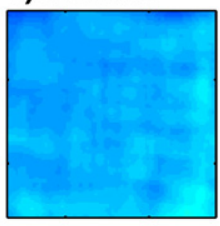

d) Profile

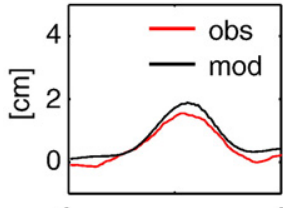

A

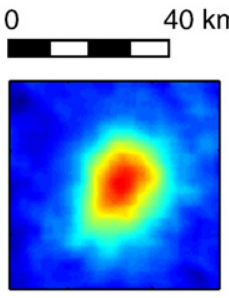

$A^{\prime}$

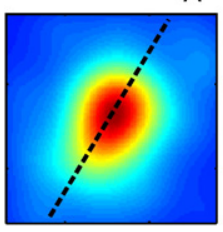

A
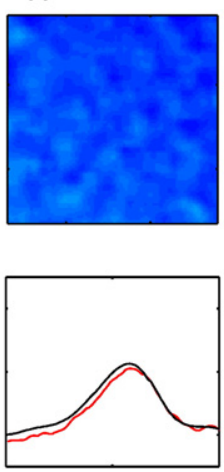
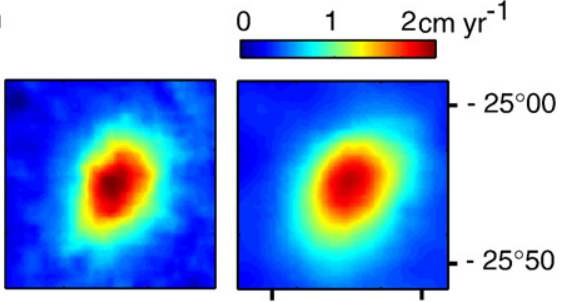

$-68^{\circ} 25-68^{\circ} 65$
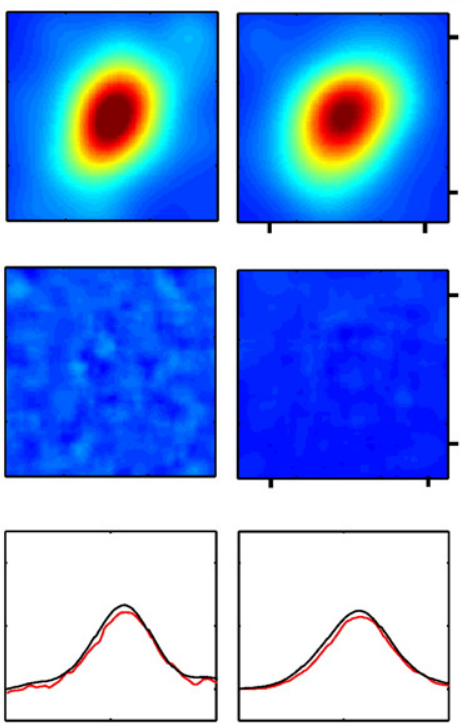

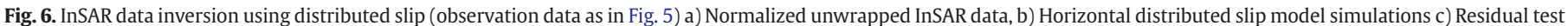
between the InSAR data and the models.

compilation of selected recent works at volcanic areas subject to inflation larger than $5 \mathrm{~km}$ in diameter. We retrieve approximate diameters from previous geodetic studies (Amelung et al., 2000; Feigl et al., 2000; Lu et al., 2000, 2002a,b,c; Pritchard and Simons, 2002; Masterlark and Lu, 2004; Pedersen and Sigmundsson, 2004; Newman et al., 2006; Lundgren and Lu, 2006; Wicks et al., 2006) and add also the dimension of the Lazufre area for the four observed periods shown in Fig. 3. Fig. 8 shows, for instance, that only a few other volcanic systems show deformations comparable in size, namely Yellowstone and Long Valley in the USA, Uzon caldera in Kamchatka and the Hualca Hualca volcanic area in Peru (Pritchard and Simons, 2002; Wicks et al., 2006; Lundgren and Lu, 2006). The Lazufre volcanic area has increased in size from about $300 \mathrm{~km}^{2}$ to $1100 \mathrm{~km}^{2}$, with an average diameter from $\sim 20 \mathrm{~km}$ to $\sim 45 \mathrm{~km}$ (Fig. 8), suggesting that Lazufre has the potential to become the largest deforming volcano system on Earth.

\subsection{Source origin}

Recent studies of caldera systems have proposed that hydrothermal activity instead of magma may cause ground displacements (Gottsmann et al., 2003; Battaglia et al., 2006; Hurwitz et al., 2007). However, Lazufre shows no evidence for major hydrothermal activity that could be responsible for the observed deformation pattern, with hydrothermalism appearing to be limited to the fumarole activity on the

Plan view : distributed slip opening at $10 \mathrm{~km}$ depth

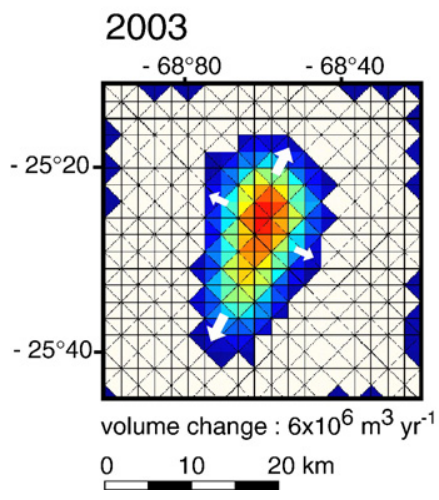

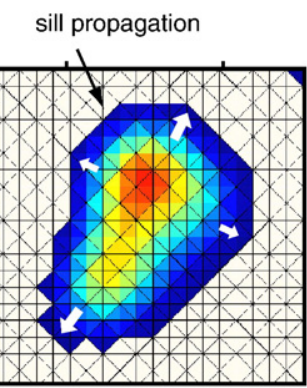

$9 \times 10^{6} \mathrm{~m}^{3} \mathrm{yr}^{-1}$

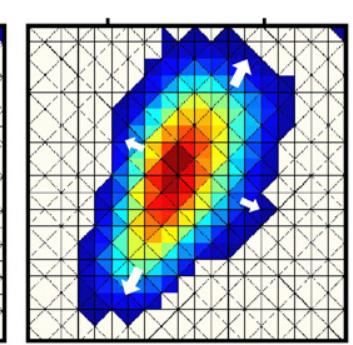

$10 \times 10^{6} \mathrm{~m}^{3} \mathrm{yr}^{-1}$

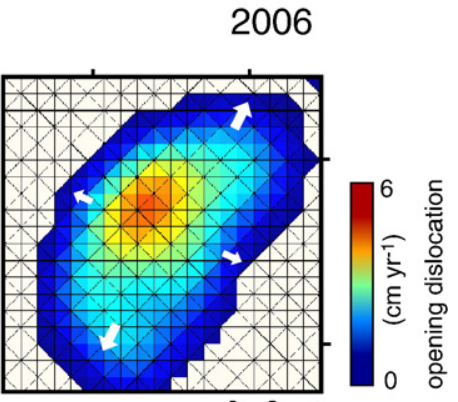

$12 \times 10^{6} \mathrm{~m}^{3} \mathrm{yr}^{-1}$

ס
Fig. 7. Dislocation plane models showing slip distribution at $10 \mathrm{~km}$ depth using normalized interferograms from 2003-2006. The peak of opening is about $6 \mathrm{~cm} \mathrm{yr}^{-1}$ for all the dislocation models, whereas the source propagates laterally at a velocity of about $1-4 \mathrm{~km} \mathrm{yr}^{-1}$. These models are consistent with a laterally expanding magma intrusion. 
Lastarria volcano (Froger et al., 2007). Moreover, we believe that due to the buoyancy of hydrothermal fluids, they may prefer a vertical propagation direction rather than the horizontal propagation as identified by our InSAR time series models. Nonetheless, ongoing ground - truth data, such as repeated microgravity campaigns and seismic studies, will help to better constrain the nature of the source.

We herein consider that the lateral expansion at depth is related to magma propagation, supposing an intrusion at the level of neutral buoyancy (Ryan, 1987). This depth is slightly deeper than that based on thermobarometry studies of the Neogene ignimbrite products in the CVZ (Central Volcanic Zone), that show evidence of mineral phases in equilibrium typically in the depth range of 5 to $9 \mathrm{~km}$ (Schilling et al., 2006). We note that the lower bound of our calculated source depth location is within this range, dependent upon the constraints applied during the inversion. Our magma intrusion hypothesis is in agreement with a study of the Puna plateau $200 \mathrm{~km}$ to the north, in which other authors propose that sub-horizontal crustal faulting is associated with mid crustal-magma sheet intrusions (Riller and Oncken, 2003).

\subsection{Earthquake triggering of magma intrusion}

Of special interest is the question, why did the inflation of the Lazufre abruptly start in 1998. A connection with a series of tectonic-based earthquakes from 1995-1998 surrounding the Lazufre area may have encouraged a possible magma intrusion (Pritchard and Simons, 2002). The megathrust M8.1 Antofagasta earthquake, which occurred in June 1995, was followed by a series of $M>6$ earthquakes along with a M7.1 event in January 1998, located $250 \mathrm{~km}$ WNW from Lazufre. These events coincide with the start of the surface deformation observed at Lazufre. Earthquakes may have reactivated pre-existing structural weak zones in the volcanic arc and, hence, destabilized an existing magma body (Walter and Amelung, 2007). Alternatively, the passing seismic waves may also have triggered a perturbation of a magma reservoir (Manga and Brodsky, 2006).

\subsection{Total volume of the source}

Due to the absence of satellite data for the period 2000-2003, it is difficult to assess the total volume of the source since the start of

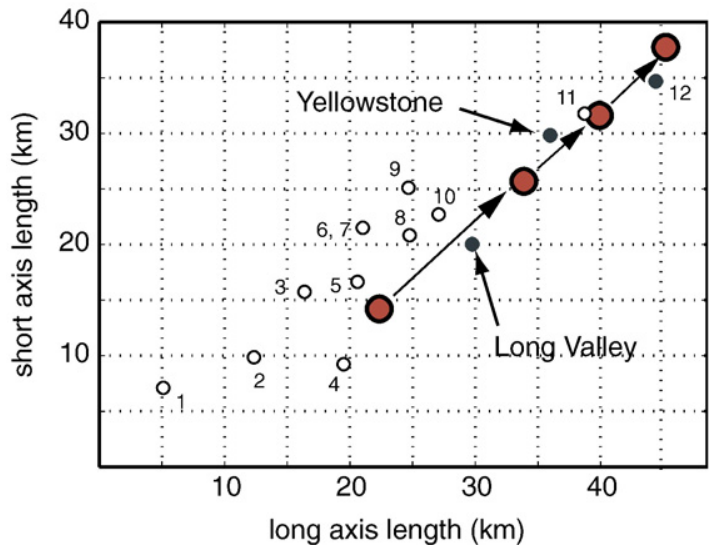

Fig. 8. Ground deformation of volcanic area larger than $5 \mathrm{~km}$ in diameter, as measured by InSAR. The periods of observations are from 1996-2000 for Yellowstone (Wicks et al., 2006); 1997-1998 for Long Valley (Newmann et al., 2006), while the red dots show the evolution of Lazufre from 2003 to 2006. The other large systems are: 1) Sierra Negra (Galapagos islands), 2) Seguam island (Alaska), 3) Hengill volcano (Iceland), 4) Three Sisters (North USA), 5) Uzon caldera (Kamchatka), 6) Makushin (Alaska), 7) Cerro Blanco (Argentina), 8) Eyjafjallajökull (Iceland), 9) Mount Peulik (Alaska), 10) Westdahl (Alaska) and 11) Uturuncu (Argentina). (For interpretation of the references to colour in this figure legend, the reader is referred to the web version of this article.)
Same surface deformation for different source dimensions

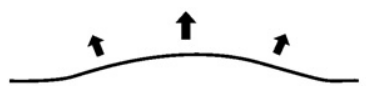

a

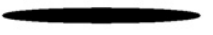

new intrusion

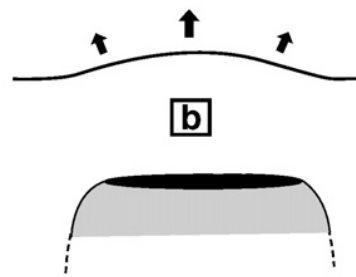

preexisting (inflating) magma chamber
Fig. 9. Two scenarios that may equally well explain the pattern of the source geometry of the surface deformation at Lazufre. a) A sill expanding laterally at depth, and b) a larger, pre-existing magma chamber inflating at depth.

deformation in 1998. ERS1/2 satellite data yield a volume-change rate of $6 \times 10^{6} \mathrm{~m}^{3} \mathrm{yr}^{-1}$ from 1998 to 2000 (Pritchard and Simons, 2004), whereas our Envisat data show that rate increases from $6 \times 10^{6} \mathrm{~m}^{3} \mathrm{yr}^{-1}$ to $12 \times 10^{6} \mathrm{~m}^{3} \mathrm{yr}^{-1}$ from 2003 to 2006 . Assuming that the rate of inflation for the period 2000 to 2003 was the same as for the period 1998-2003 and then increased from 2003 to 2006, a total volume of $0.05 \mathrm{~km}^{3}$ may have been accumulated. This result is only representative of the difference in volume $(\Delta V)$ after a perturbation of the source. We emphasize that this does not necessary suggest a thin sill intrusion. We hypothesize that the source of the deformation could alternatively be related to the inflation of a larger, pre-existing magma body previously in a state of equilibrium (Fig. 9). Earlier studies at a Galapagos caldera illustrated that a large magma chamber with a flat roof can produce the same amount and pattern of surface displacement as a thin sill (Yun et al., 2006). The finite source of the deformation at Lazufre may therefore be much larger than the volume change estimation presented here.

Evaluation of the thermal cooling of a magma body in a host rock may provide further insights on the dimension of the magma body (using standard thermal cooling estimates and ignoring the latent heat, see equations 4-149 to 4-150 in Turcotte and Schubert, 2002). Our InSAR data can be explained by a sill intruding at a rate of $6 \mathrm{~cm} \mathrm{yr}^{-1}$ with a length of $35 \mathrm{~km}$. If we consider a difference of temperature of $1000 \mathrm{~K}$ between the host rock and a sheet-like intrusion, the latter will completely solidify in about $1.5 \mathrm{~h}$. InSAR data, however, shows a constant inflation over a time series of 9 years, implying that the magma body must be larger in order to remain fluid. We now follow an approach applied by Yun et al. (2006) and inversely calculate the minimum magma chamber thickness required for 9 years long intrusion duration. Assuming that the source of the Lazufre deformation has been constantly active since 1998-2006, the initial thickness of the magma chamber would have been at least $30 \mathrm{~m}$ (for a $1000 \mathrm{~K}$ temperature difference). Based on this result, the volume of the source would have been at least $6 \mathrm{~km}^{3}$. These models are very simplified, but provide a first-order estimation of a much larger and yet realistic magma body volume.

\section{Conclusion}

InSAR data reveal a wide, elliptical ground inflation area with a long axis $\sim 45 \mathrm{~km}$ in length and a LOS displacement of up to $3 \mathrm{~cm} \mathrm{yr}^{-1}$. The volume and area involved suggest a continuously-increasing rate since 2003. We interpret the source of the inflation as a magma body up to $30 \mathrm{~km}$ in diameter, located at about $10 \mathrm{~km}$ depth. Even though it is unclear if this rapid and wide deformation is a precursor of an eruption at Lazufre, this study implies that apparently inactive zones may become subject to deformation and develop into large dimension systems within a matter of a few years. The total volume of the entire magma body remains unclear. The InSAR data shows a volume change 
of $0.05 \mathrm{~km}^{3}$, which probably reflects only a minor part of a larger magma reservoir.

\section{Acknowledgements}

We are grateful to Paul Lundgren and an anonymous reviewer for their constructive comments which helped us to improve the manuscript and we appreciate the discussions with Andrea Manconi. Envisat data were provided by the European Space Agency as part of category 1 project \# 3455. The Research has been partially funded by the Deutsche Forschungsgemeinschaft (Emmy Noether grant, DFG \#WA1642 and \# MO1851/1-1), and the Geotechnologien programme 265.

\section{References}

Ambrose, S.H., 1998. Late Pleistocene human population bottlenecks, volcanic winter, and differentiation of modern humans. Journal of Human Evolution 34 (6), 623-651.

Amelung, F., Jonsson, S., Zebker, H., Segall, P., 2000. Widespread uplift and "trapdoor" faulting on Galapagos volcanoes observed with radar interferometry. Nature 407 (6807), 993-998.

Battaglia, M., Troise, C., Obrizzo, F., Pingue, F., De Natale, G., 2006. Evidence for fluid migration as the source of deformation at Campi Flegrei caldera (Italy). Geophysical Research Letters 33 (L01307). doi:10.1029/2005GL024904.

Bürgmann, R., Rosen, P., Fielding, E., 2000. Synthetic aperture radar interferometry to measure Earth's surface topography and its deformation. Annual Review of Earth and Planetary Sciences 28, 169-209.

Cole, J.W., Milner, D.M., Spinks, K.D., 2005. Calderas and caldera structures; a review. Earth-Science Reviews 69 (1-2), 1-26.

de Silva, S.L., 1989. Altiplano-Puna volcanic complex of the Central Andes. Geology 17 (12), 1102-1106.

Dieterich, J., Decker, R., 1975. Finite element modeling of surface deformation associated with volcanism. Journal of Geophysical Research 80 (29), 4094-4102.

Feigl, K.L., Gasperi, J., Sigmundsson, F., Rigo, A., 2000. Crustal deformation near Hengill Volcano, Iceland 1993-1998; coupling between magmatic activity and faulting inferred from elastic modeling of satellite radar interferograms. Journal of Geophysical Research 105 (11), 25,655-25,670.

Francis, P.W., de, S.S.L., Mouginis, M.P.J., Self, S., 1989. Large diameter volcanic spatter rings; mechanisms of origin and significance for planetary studies, abstracts. Lunar and Planetary Science Conference, Houston, TX, United States, pp. 307-308.

Froger, J.L., Remy, D., Bonvalot, S., Legrand, D., 2007. Two scales of inflation at LastarriaCordon del Azufre volcanic complex, cenral Andes, revealed from ASAR-ENVISAT interferometric data. Earth and Planetary Science Letters 255 (1-2), 148-163.

Gottsmann, J., Berrino, G., Rymer, H., Williams, J.G., 2003. Hazard assessment during caldera unrest at the Campi Flegrei, Italy; a contribution from gravity-height gradients. Earth and Planetary Science Letters 211 (3-4), 295-309.

Hanssen, R., 2001. Radar Interferometry data interpretation and data analysis. Kluwer academic publishers, Dordrecht. 308 pp.

Hurwitz, S., Christiansen, L.B., Hsieh, P.A., 2007. Hydrothermal fluid flow and deformation in large calderas: inferences from numerical simulations. Journal of Geophysical Research 112 (B02206). doi:10.1029/2006JB004689.

Ingebritsen, S.E., Sherrod, D.R., Mariner, R.H., 1989. Heat flow and hydrothermal circulation in the Cascade Range, north-central Oregon. Science 243 (4897), 1458-1462.

Lipman, P.W., 1997. Subsidence of ash-flow calderas: relation to caldera size and magma-chamber geometry. Bulletin of Volcanology 59 (3), 198-218.

Lipman, P.W., 2000. Calderas, Encyclopedia of volcanoes. Academic Press, San Diego, CA, United States.

Lu, Z., Masterlark, T., Dzurisin, D., Rykhus, R., Wicks Jr., C., 2000. Magma supply dynamics at Westdahl Volcano, Alaska, modeled from satellite radar interferometry. Geophysical Research Letters 27 (11), 1567-1670.

Lu, Z., Masterlark, T., Dzurisin, D., Wicks, C., 2002a. Subsidence at Kiska Volcano, western Aleutians, detected by satellite radar interferometry. Geophysical Research Letters 29. doi:10.1029/2002GL014948.

Lu, Z., Power, J.A., McConnell, V.S., Wicks Jr., C., Dzurisin, D., 2002b. Preeruptive inflation and surface interferometric coherence characteristics revealed by satellite radar interferometry at Makushin Volcano, Alaska; 1993-2000. Journal of Geophysical Research 107. doi:10.1029/2001JB000970.

Lu, Z., et al., 2002c. Magmatic inflation at a dormant stratovolcano; 1996-1998 activity at Mount Peulik Volcano, Alaska, revealed by satellite radar interferometry. Journal of Geophysical Research 107. doi:10.1029/2001JB000471.

Lundgren, P., Lu, Z., 2006. Inflation model of Uzon caldera, Kamchatka, constrained by satellite radar interferometry observations. Geophysical Research Letters 33 (L06301). doi:10.1029/2005GL025181.

Maerten, F., Resor, P., Pollard, D., Maerten, L., 2005. Inverting for slip on three-dimensional fault surfaces using angular dislocations. Bulletin of the Seismological Society of America 95 (5), 1654-1665.

Manconi, A., Walter, T.R., Amelung, F., 2007. Effects of mechanical layering on volcano deformation. Geophysical Journal International 170 (2), 952-958. doi:10.1111/ j.1365-246X.2007.03449.x.

Manga, M., Brodsky, E., 2006. Seismic triggering of eruptions in the far field; volcanoes and geysers. Annual Review of Earth and Planetary Sciences (34), 263-291.

Marsh, B.D., 2000. Magma chambers, Encyclopedia of volcanoes. Academic Press, San Diego, CA, United States.

Massonnet, D., Feigl, K.L., 1998. Radar interferometry and its application to changes in the Earth's surface. Reviews of Geophysics 36 (4), 441-500.

Masterlark, T., Lu, Z., 2004. Transient volcano deformation sources imaged with interferometric synthetic aperture radar; application to Seguam Island, Alaska. Journal of Geophysical Research 109. doi:10.1029/2003JB002568.

Newhall, C.G., Dzurisin, D., 1988. Historical unrest at large calderas of the world. USGS Bulletin 1855, 1108.

Newman, A.V., Dixon, T.H., Gourmelen, N., 2006. A four-dimensional viscoelastic deformation model for Long Valley Caldera, California, between 1995 and 2000. Journal of Volcanology and Geothermal Research 150, 244-269.

Ort, M.H., Coira, B.L. Mazzoni, M.M. 1996. Generation of a crust-mantle magma mixture; magma sources and contamination at Cerro Panizos, central Andes. Contributions to Mineralogy and Petrology 123 (3), 308-322.

Pedersen, R., Sigmundsson, F., 2004. InSAR based sill model links spatially offset area of deformation and seismicity for the 1994 unrest episode at Ejyafjallajokull Volcano, Iceland. Geophysical Research Letters 31. doi:10.1029/2004GL020368.

Pritchard, M.E., Simons, M., 2002. A satellite geodetic survey of large-scale deformation of volcanic centres in the central Andes. Nature 418 (6894), 167-171.

Pritchard, M.E., Simons, M., 2004. An InSAR-based survey of volcanic deformation in the southern Andes. G3 5 (2), 1-42.

Reigber, A., Moreira, J., 1997. Phase unwrapping by fusion of local and global methods. Proceedings of IGARSS'97, pp. 869-871.

Riller, U., Oncken, O., 2003. Growth of the central Andean plateau by tectonic segmentation is controlled by the gradient in crustal shortening. Journal of Geology 111 (3), 367-384.

Ryan, M.P., 1987. Neutral buoyancy and the mechanical evolution of magmatic systems, magmatic processes: physicochemical principles. Geochemical Society 259-287.

Schilling, F.R., et al., 2006. Partial melting in the Central Andean Crust: a review of geophysical, petrophysical, and petrologic evidence. In: Oncken, O., et al. (Ed.), The Andes - Active Subduction Orogeny. Springer, pp. 459-474.

Siebert, L., Simkin, T., 2002. Volcanoes of the world: an illustrated catalog of Holocene volcanoes and their eruptions. Smithsonian Institution, Global Volcanism Program, Digital Information Series, GVP-3. http://www.volcano.si.edu/world/.

Tarantola, A., 1987. Inverse problem theory, method for data fitting and model parameter estimation. Elsevier, p. 613.

Thomas, A.L., 1993. Poly3D: A three-dimensional, polygonal element, displacement discontinuity boundary element computer program with applications to fractures, faults, and cavities in the Earth's crust. M.S. Thesis, pp. 105-110.

Turcotte, D.L., Schubert, G., 2002. Geodynamics, second edition. Cambridge University Press, Cambridge, UK, p. 456.

Walter, T.R., Amelung, F., 2007. Volcanic eruptions following $\mathrm{M}>$ or $=9$ megathrust earthquakes; implications for the Sumatra-Andaman volcanoes. Geology 35 (6), 539-542.

Wicks, C.W., Thatcher, W., Dzurisin, D., Svarc, J., 2006. Uplift, thermal unrest and magma intrusion at Yellowstone caldera. Nature 440, 72-75.

Williams, H., 1941. Calderas and their origin. University of California Publications in Geological Sciences 25 (6), 239-346.

Yun, S., Segall, P., Zebker, H., 2006. Constraints on magma chamber geometry at Sierra Negra Volcano, Galapagos Islands, based on InSAR observations. Journal of Volcanology and Geothermal Research 150, 232-243. 